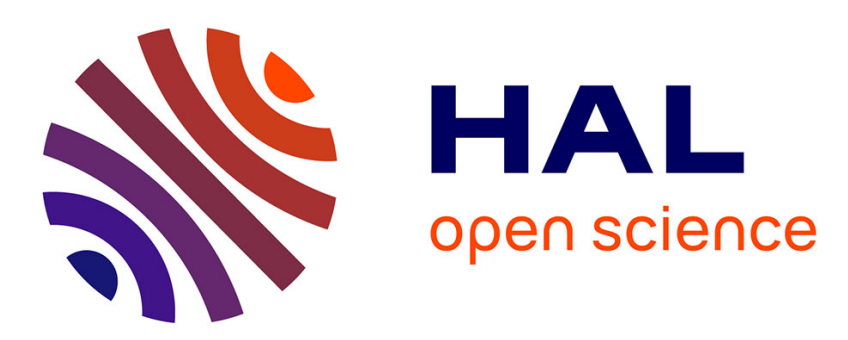

\title{
Evaluation of scanning transmission X-ray microscopy at the Mn L2,3-edges as a potential probe for manganese redox state in natural silicates
}

Franck Bourdelle, Emily Lloret, Cyril Durand, Laura Airaghi

\section{- To cite this version:}

Franck Bourdelle, Emily Lloret, Cyril Durand, Laura Airaghi. Evaluation of scanning transmission Xray microscopy at the $\mathrm{Mn} \mathrm{L} 2,3$-edges as a potential probe for manganese redox state in natural silicates. Physics and Chemistry of Minerals, 2021, 48 (4), 10.1007/s00269-021-01142-w . insu-03192509

\section{HAL Id: insu-03192509 \\ https://hal-insu.archives-ouvertes.fr/insu-03192509}

Submitted on 8 Apr 2021

HAL is a multi-disciplinary open access archive for the deposit and dissemination of scientific research documents, whether they are published or not. The documents may come from teaching and research institutions in France or abroad, or from public or private research centers.
L'archive ouverte pluridisciplinaire $\mathbf{H A L}$, est destinée au dépôt et à la diffusion de documents scientifiques de niveau recherche, publiés ou non, émanant des établissements d'enseignement et de recherche français ou étrangers, des laboratoires publics ou privés. 
1 Title: Evaluation of scanning transmission X-ray microscopy at the Mn L2,3-edges as a

2 potential probe for manganese redox state in natural silicates

3

4 Authors: Franck Bourdelle ${ }^{\mathrm{a}, *}$, Emily Lloret $^{\mathrm{a}}$, Cyril Durand ${ }^{\mathrm{a}}$, Laura Airaghi ${ }^{\mathrm{b}}$

5

6 Affiliations:

$7 \quad{ }^{a}$ Univ. Lille, Institut Mines-Télécom, Univ. Artois, Junia, ULR 4515 - LGCgE, Laboratoire

8 de Génie Civil et géo-Environnement, F-59000 Lille, France

$9 \quad{ }^{\mathrm{b}}$ University of Orléans, CNRS, BRGM, ISTO, UMR 7327, F-45071, Orléans, France

10

$11 *$ Corresponding authors:

12 Dr. Franck Bourdelle

13 Present mailing address: Laboratoire Génie Civil et géo-Environnement (LGCgE) -

14 Département des Sciences de la Terre, Université de Lille, Cité Scientifique, Bâtiment SN5,

1559655 Villeneuve d'Ascq Cedex, France.

16 E-mail address: franck.bourdelle@ univ-lille.fr

17 Phone number: + $33(0) 320434113$

18

19 ORCID:

20 Franck Bourdelle: 0000-0002-7136-8692

21 Emily Lloret: 0000-0003-0952-9202

22 Cyril Durand: 0000-0001-8341-8450

23 Laura Airaghi: 0000-0001-7032-2732 


\section{Abstract}

Determining the Mn valence variation at the nanometer scale will be an important advance in the study of heterogeneous natural silicates. Here, the potential of the scanning transmission

$31 \mathrm{X}$-ray microscopy at the $\mathrm{Mn} \mathrm{L}_{2,3}$-edges $(640-655 \mathrm{eV})$ as a probe for manganese redox state is evaluated. For this purpose, several natural Mn-silicates (rhodonite, ardennite, piemontite, $\mathrm{Mn}^{4+}$-silicate, jacobsite), covering several Mn valence, were analysed to identify the spectral parameters most sensitive to the Mn valence, regardless of the coordination environment, the crystal field strength, the nature and the length of the metal-ligand bonds, and the intraatomic Coulomb and spin-orbit interactions. Two suitable spectral empirical calibrations are thus proposed, linking the Mn valence to two peak intensity ratios: one ratio of intensities from two energy points of the $\mathrm{L}_{2}$ peak (at 651.7 and $655.2 \mathrm{eV}$ ), and one ratio of intensities from one energy point of the $\mathrm{L}_{2}$ peak (at $655.2 \mathrm{eV}$ ) and one of the $\mathrm{L}_{3}$ peak (at $641.6 \mathrm{eV}$ ). Thank to them, the first quantitative Mn valence maps are constructed, with a high spatial resolution (<40 nm pixel size), opening the way to exhaustive crystallochemical studies of silicates containing Mn with different valences.

Key words: manganese valence; STXM; XANES spectroscopy; $\mathrm{L}_{2,3}$-edges; redox mapping; silicates 
48 Funding: This study was financially supported by LGCgE (laboratory funds).

49 Conflicts of interest/Competing interests: Not applicable.

50 Availability of data and material: XANES spectra are available on request from

51 franck.bourdelle@univ-lille.fr

52 Code availability: Not applicable.

53 Authors' contributions (optional): - 


\section{Introduction}

Constraining redox conditions during sediment deposition, rock formation or mineralogical transformation is of primary importance to understand the P-T-X history (pressure-temperature-composition) of geological systems. Redox conditions are usually assessed by the analysis of minerals since they partly influence their chemical composition.

The evaluation of redox conditions is often based on the iron redox state, i.e. by the quantification of the $\mathrm{Fe}^{3+} / \mathrm{Fe}^{2+}$ ratio in minerals - mainly silicates, major constituents of crusts - when they can contain both divalent and trivalent cations (i.e. Inoue et al. 2018). More rarely, the redox state of other metals is investigated, as manganese. However, $\mathrm{Mn}-$ which can be present as $\mathrm{Mn}^{2+}, \mathrm{Mn}^{3+}$ and sometimes-but-rarely $\mathrm{Mn}^{4+}-$ could be a good indicator of paleo-conditions of rock formation (Loomer et al. 2007), even if Mn-silicates, specially P-T$\mathrm{X}$ sensitive silicate solid solution such as phyllosilicates, are infrequent, at the very least not ubiquitous in sedimentary and metamorphic rocks, and that the Mn content of these silicates is low. In this way, Sussenberger et al. (2018) suggest that Mn content in chlorite could be a proxy for chemo-stratigraphic conditions in depositional environment. For their part, Bobos et al. (2018) establish a link between Mn-chlorite and Wolframite, the Mn content in chlorite becoming an indicator of W-Mo mineralisation.

Unfortunately, authors could not determine the $\mathrm{Mn}^{3+} / \mathrm{Mn}^{2+}$ ratio which would have noticeably modified the chlorite structural formula calculation, and potentially the subsequent interpretations. In the past, different techniques have been envisaged for this purpose, including electron microprobe analysis (EMPA, e.g. Albee and Chodos 1970), X-ray photoelectron spectroscopy (XPS, e.g., Ilton et al. 2016) or X-ray absorption near edge structure (XANES) spectroscopy at the K-edge (e.g. Manceau and Gallup 2005; Manceau et al. 2012). However, none of these methods provides a nanometer-scale spatial resolution, which could be particularly useful to identify chemical and redox zonation patterns in lowtemperature crystals (e.g. Bourdelle et al. 2018). On the other hand, several studies (e.g., Garvie and Craven 1994; van Aken and Liebscher 2002) have shown that electron energy-loss 
spectroscopy (EELS) carried out in a transmission electron microscope (TEM) is a powerful method for determining the redox state of transition metals at a submicrometric resolution, including $\mathrm{Mn}$ in silicates, but sometimes induces severe beam damage effects, such as electron beam-induced reduction of manganese (Lauterbach et al. 2000; de Groot et al. 2010; Livi et al. 2012). The XANES spectroscopy at the $\mathrm{L}_{2,3}$-edges is often proposed as a powerful alternative and is increasingly used in the Earth sciences. Firstly, the X-ray energies required for XANES analysis are lower at the $\mathrm{L}_{2,3}$-edges (between $\sim 640$ and $655 \mathrm{eV}$ ) than at the Kedge (between $\sim 6500$ and $6580 \mathrm{eV}$ ), allowing higher resolutions, i.e. $<0.1 \mathrm{eV}$ and $\sim 30 \mathrm{~nm}$ at existing synchrotron facilities. Secondly, the X-ray incident beam is less destructive for samples than the TEM-EELS electron beam.

The XANES spectroscopy at the $\mathrm{L}_{2,3}$-edges is based on the $2 p \rightarrow 3 d$ electronic transition, which is sensitive to - among other parameters - the metal valence (e.g. Garvie and Craven 1994). De Groot et al. (1994) describing in detail the complex physical basis of Mn $\mathrm{L}_{2,3}$-edges, underlined that $\mathrm{Mn}$ valence can be obtained from $\mathrm{L}_{2,3}$-edge spectra by a multiplet calculation. However, this approach remains difficult to use in the case of natural minerals whose structure has not been beforehand determined. Otherwise, the Mn valence can be evaluated by fitting $\mathrm{L}_{2,3}$-edge spectra with a combination of reference spectra, but this requires $\mathrm{Mn}^{2+}, \mathrm{Mn}^{3+}, \mathrm{Mn}^{4+}$ reference compounds, with $\mathrm{Mn}$ in the same local coordination environment than the studied sample. Consequently, several authors have turned to empirical approaches, trying to find a spectral parameter depending only (or at least, mainly) on the Mn valence. The white-line ratio, calibrated by van Aken and Liebscher (2002), is probably the best known, linking the formal transition metal valence to the ratio of integral intensity (over a $2 \mathrm{eV}$ window) of the $\mathrm{L}_{3}$ and $\mathrm{L}_{2}$ excitation peaks. Recently, Wang et al. (2018) used the integrated L-edge intensity, considering it is proportional to the total number of $3 d$ holes localized in the X-ray absorber (normalized to this invariant edge jump), while Risch et al. (2017) proposed a linear correlation between Mn valence and the energy of the center of gravity of the Mn L3-edge. But these methods, a review of which was proposed by Tan et al. 
(2013), were often calibrated for Mn-oxides, but were not tested on Mn-silicates, which

109 present specific structures.

Moreover, synchrotron facilities make possible to carry out Mn L2,3-edge XANES spectroscopy with a scanning transmission X-ray microscope (STXM), one spectrum being one image pixel of the studied sample area (e.g. Bourdelle et al. 2013). This makes it possible to consider extracting quantitative maps of Mn valence over the entire area of interest, very useful for heterogeneous natural samples containing mixed oxidation state Mn species. Pecher et al. (2003) explore the feasibility of such maps extracted from STXM-XANES data, in order to characterize the Mn charge state distribution in biominerals. Unfortunately, in absence of empirical calibration based on a spectral intensity ratio rather than an integrated area or a center of gravity calculation, the resulting maps remain qualitative.

From these observations, we want to evaluate the potential of the scanning transmission X-ray microscopy at the $\mathrm{Mn}_{2,3}$-edges as a probe for manganese redox state investigations in natural silicates, defining a suitable spectral empirical calibration allowing to construct quantitative Mn valence maps with a high spatial resolution (nanoscale).

\section{Materials and methods}

\subsection{Natural samples}

Samples used in this study were natural silicates, containing various Mn amount and covering the three common Mn redox state $(2+, 3+, 4+)$. As the shape of the $\mathrm{Mn} \mathrm{L}_{2,3}$-edge spectra can be influenced by, among others parameters, the Mn coordination, one oxide presenting $\mathrm{Mn}$ in tetrahedral coordination sites is also considered. Particles transparent to soft X-rays are needed to measure XANES spectra in the transmission mode of STXM, therefore samples are prepared as grounded powders dispersing in ethanol; a drop of which is placed (then evaporated) on a carbon holey support film placed on a 200 mesh copper grid.

The selected silicates are rhodonite, ardennite, piemontite and a $\mathrm{Mn}^{4+}$-silicate (Table 1), for which chemical composition has been verified by Energy-dispersive X-ray 

200 SEM instrument operating at $15 \mathrm{kV}$ with a $1.5 \mathrm{nA}$ current; mineral standards used for EDX probe calibration: albite, diopside, orthoclase, garnet and $\mathrm{MnTiO}_{3} ; \mathrm{ZAF}$ correction applied). Rhodonite is a $\mathrm{Mn}^{2+}$ pyroxenoid, where $\mathrm{Mn}$ is mainly in 6 coordination, sometimes in 7 (Smyth and Bish 1988; Nelson and Griffen 2005). Mn is therefore in distorted octahedral

140 sites, defined by Mn-O bonds. The rhodonite sample used here, whose formula is

$141 \mathrm{Ca}_{0.15} \mathrm{Mn}_{0.85} \mathrm{SiO}_{3}$, comes from Gambaseta (Liguria, Italia). Ardennite is a $\mathrm{Mn}^{2+}$ sorosilicate

142 described by the following formula: $\mathrm{Mn}_{4} \mathrm{Al}_{4}(\mathrm{AlMg})\left(\mathrm{AsO}_{4}\right)\left(\mathrm{SiO}_{4}\right)_{2}\left(\mathrm{Si}_{3} \mathrm{O}_{10}\right)(\mathrm{OH})_{6}$. In it, $\mathrm{Mn}$ is

143 located in large polyhedron, based on 5 coordination via Mn-O bonds, and 2 additional

144 coordination via Mn-OH bonds (Donnay and Allmann 1968). Here, one specimen of As-

145 Ardennite from Salm-Château (Ardennes, Belgium) was studied; the composition does not

146 present an excess of $\mathrm{Mn}(<4$ atoms per formula unit), all Mn is consequently assumed as

$147 \mathrm{Mn}^{2+}$ (Nagashima and Armbruster 2020). Piemontite is a Mn-rich epidote, where Mn is in

148 trivalent form and occupies octahedral sites. The selected specimen comes from the Prabornaz

149 mine (Aosta, Italia), with the verified chemical formula

$150 \mathrm{Ca}_{2.05}\left(\mathrm{Al}_{1.68} \mathrm{Fe}^{3+}{ }_{0.49} \mathrm{Mn}^{3+}{ }_{0.83}\right)\left(\mathrm{Si}_{2.0} \mathrm{O}_{7}\right)\left(\mathrm{Si}_{1.0} \mathrm{O}_{4}\right) \mathrm{O}(\mathrm{OH})$. The last studied Mn-silicate, a rare type

151 of silicates that contains tetravalent Mn similarly to stavelotite-(La), was sampled at

152 Eveslogchorr (Murmansk Oblast, Russia) combined with pectolite and has the determined

153 empirical formula: $\mathrm{Na}_{0.3} \mathrm{Ca}_{1.4} \mathrm{Fe}^{3+}{ }_{0.3} \mathrm{Mn}^{4+}{ }_{5} \mathrm{SiO}_{14}$. A jacobsite sample, from Langban, (Filipstad,

154 Sweden), was also analysed. Jacobsite is an $\mathrm{Mn}^{2+}$ oxide belonging to the spinel group, with

155 the common formula $\mathrm{MnFe}_{2} \mathrm{O}_{4}$. As a "normal spinel", $\mathrm{Mn}^{2+}$ occupies tetrahedral sites formed 156 by 4 oxygens (Bosi et al. 2019).

158 Table 1: Samples used for STXM-XANES Mn $\mathrm{L}_{2,3}$-edge investigations to Mn mean valence 159 quantification

\begin{tabular}{llllll}
\hline Type & Sample & Location & $\begin{array}{l}\text { Mn } \\
\text { valence }\end{array}$ & \multicolumn{2}{l}{$\begin{array}{l}\text { Position of major } \\
\text { peaks }(\mathrm{eV})\end{array}$} \\
\cline { 4 - 7 } & & & $\mathrm{L}_{3}$ & $\mathrm{~L}_{2}$ \\
\hline Silicate & Rhodonite & Gambaseta (Liguria, Italia) & $2+$ & 641.6 & 654.1 \\
\hline
\end{tabular}




\begin{tabular}{llllll}
\hline Silicate & Ardennite & Salm-Château (Ardennes, Belgium) & $2+$ & 641.6 & 654.1 \\
Silicate & Piemontite & Prabornaz mine (Aosta, Italia) & $3+$ & 643.2 & 654.4 \\
Silicate & $\mathrm{Mn}^{4+}$-silicate & Eveslogchorr (Murmansk Oblast, Russia) & $4+$ & 644.6 & 655.2 \\
Oxide & Jacobsite & Langban (Filipstad, Sweden) & $2+$ & 641.6 & 654.1 \\
\hline
\end{tabular}

\subsection{STXM and XANES spectroscopy}

The STXM is able to record the transmitted soft X-ray intensity on each point of the

163 pluri-micrometric-sized area of interest for each defined energy. Therefore, STXM gives 2D

164 images for which each pixel represents a soft X-ray absorption spectrum. This is of great

165 interest for mapping metal oxidation state variation into small crystallites (e.g. Bourdelle et al.

166 2013). In the present study, STXM analyses were acquired on the PolLux beamline at the

167 Swiss Light Source (SLS, Villigen, Switzerland). The characteristics of the beamline are

168 detailed by Raabe et al. (2008); the beam was in circular-polarisation configuration to avoid

169 crystal lattice orientation dependency of analysis (see below). The scanning transmission X-

170 ray microspectroscopy endstation allows to achieve stacks and linescans, i.e. a spectral map of

171 an area and a sum of spectra for each pixel of a line, respectively. Stacks were recorded over

172 the 635-660 eV energy range ( $\mathrm{Mn} \mathrm{L}_{2,3}$-edge) using a $0.2 \mathrm{eV}$ spectral resolution and a $40 \mathrm{~nm}$

173 spatial resolution. Linescans were recorded over the same energy range, using a $0.1 \mathrm{eV}$

174 spectral resolution. The dwell time per image- and energy- point was between 1 and $10 \mathrm{~ms}$.

175 Focus was checked systematically for each particle. STXM-XANES data were post-processed

176 using the aXis2000 software (Hitchcock 2012). Beam damages caused by the incident beam

177 were assessed by monitoring spectral changes at the $\mathrm{Mn} \mathrm{L}_{2,3}$-edges with increasing dwell

178 times up to $20 \mathrm{~ms}$.

\subsection{Spectrum processing}

Spectra were extracted from stacks and linescans in form of optical density spectra

182 (noted OD), obtained as $\mathrm{OD}=-\ln \left(I / I_{0}\right)$, where $\mathrm{I}$ is the $\mathrm{X}$-ray intensity transmitted from the

183 sample, and $\mathrm{I}_{0}$ is those recorded without samples. Then two steps of processing were applied

184 on spectra: 
(i) a linear background correction was applied to remove the contribution of lower energy absorption edges, so that the pre-edge region is set to 0 optical density.

(ii) the two edge steps resulting from transitions to unoccupied states in the continuum were subtracted using a double arctan function (Chen et al. 1995; van Aken and Liebscher 2002; Brotton et al. 2007) as:

$f(\Delta E)=\frac{h_{1}}{\pi}\left(\tan ^{-1}\left[\frac{\pi}{w_{1}}\left(\Delta E-E_{1}\right)\right]+\frac{\pi}{2}\right)+\frac{h_{2}}{\pi}\left(\tan ^{-1}\left[\frac{\pi}{w_{2}}\left(\Delta E-E_{2}\right)\right]+\frac{\pi}{2}\right)$

where $h_{1}$ and $h_{2}$ are the step heights of the two arctan functions, $w_{1}$ and $w_{2}$ are fixed peak widths and $E_{1}$ and $E_{2}$ are the positions of the inflection points resulting in an energy near the edge onset. Brotton et al. (2007) proposed setting the function slope $w$ at $5 \mathrm{eV}$, to account for the slow onset of the continuum. Following this recommendation, $w_{1}$ and $w_{2}$ were fixed to 5 $\mathrm{eV}$. For each sample, four or five spectra on different particles were extracted to evaluate the spectral variability. A total of 23 spectra were thus used in this study.

\section{Results and discussion}

3.1. Influences of $\mathrm{Mn}$ redox state, coordination and atomic environment on the shape of $\mathrm{Mn}$ $\mathrm{L}_{2,3}$-edge XANES spectrum X-ray absorption near edge structure spectra at the $\mathrm{Mn} \mathrm{L}_{2,3}$-edges for Mn-silicates and jacobsite are shown in Figure 1, where peaks are identified by letters (from $\mathrm{L}_{3}$-a to $\mathrm{L}_{3}-\mathrm{h}$ and from $\mathrm{L}_{2}$-a to $\mathrm{L}_{2}-\mathrm{e}$ ) and linear background is subtracted. These spectra result from transitions from $2 p$ core electrons to $3 d$ state, $4 s$ state or continuum as follow:

two strong absorption peaks, usually noted $\mathrm{L}_{3}$ and $\mathrm{L}_{2}$, due to the spin-orbit splitting of $2 p$ level (van Aken and Liebscher 2002; Nishida et al. 2013) involving transitions from $2 p_{3 / 2}$ and $2 p_{1 / 2}$ states to empty $3 d$ atomic orbitals, respectively. From a $2 p^{6} 3 d^{n}$ ground state, the absorption process leads to a core-excited $2 p^{5} d^{n+1}$ final state, as $3 d^{5}$ for $\mathrm{Mn}^{2+}, 3 d^{4}$ for $\mathrm{Mn}^{3+}$ and $3 d^{3}$ for $\mathrm{Mn}^{4+}$, implying variations in absorption energy. 
- $\quad$ edge jump steps at the bottom of $\mathrm{L}_{3}$ and $\mathrm{L}_{2}$ peaks, corresponding to $2 p \rightarrow$ continuum transitions.

- negligible contributions of $2 p \rightarrow 4 s$ transitions, which are 20 times weaker in intensity than $2 p \rightarrow 3 d$ transitions.

Each $\mathrm{L}_{3}$ and $\mathrm{L}_{2}$ peak consists of one major peak accompanied on both sides by several minor peaks. The energy position of these major peaks mainly depends (but not only) on the core-excited final state, i.e. Mn redox state: 641.6 and $654.1 \mathrm{eV}$ for $\mathrm{Mn}^{2+}\left(\mathrm{L}_{3}-\mathrm{b}\right.$ and $\mathrm{L}_{2}-\mathrm{c}$, respectively; rhodonite, ardennite, jacobsite), 643.2 and $654.4 \mathrm{eV}$ for $\mathrm{Mn}^{3+}\left(\mathrm{L}_{3}-\mathrm{e}\right.$ and $\mathrm{L}_{2}-\mathrm{d}$, respectively; piemontite), 644.6 and $655.2 \mathrm{eV}$ for $\mathrm{Mn}^{4+}\left(\mathrm{L}_{3}-\mathrm{f}\right.$ and $\mathrm{L}_{2}-\mathrm{e}$, respectively; $\mathrm{Mn}^{4+}-$

silicate). In this way, spectra are qualitatively similar to those described in several previous studies, obtained using different analytical techniques (e.g. Garvie and Craven 1994; Morales et al. 2004; Zhang et al. 2010; Kubin et al. 2018).

Minor peaks arise from factors other than redox as their number, intensity and shape vary from one sample to another. Therefore, $\mathrm{Mn}^{2+}$ spectra present 3 minor peaks $\left(\mathrm{L}_{3}-\mathrm{a}, \mathrm{L}_{3}-\mathrm{d}\right.$ and $\mathrm{L}_{3}-\mathrm{g}$ with a shoulder peak noted $\left.\mathrm{L}_{3}-\mathrm{h}\right)$ around $\mathrm{L}_{3}-\mathrm{b}$, and 2 minor peaks $\left(\mathrm{L}_{2}-\mathrm{a}, \mathrm{L}_{2}-\mathrm{b}\right)$ before $\mathrm{L}_{2}$-c, more intensive (related to the intensity of major peaks) for rhodonite than for ardennite. $\mathrm{Mn}^{3+}$ and $\mathrm{Mn}^{4+}$ spectra have fewer minor peaks: only two, at the same (or very close) energy position than the $\mathrm{L}_{3}$ and $\mathrm{L}_{2} \mathrm{Mn}^{2+}$ major peaks, and one more at $642.3 \mathrm{eV}\left(\mathrm{L}_{3}-\mathrm{c}\right)$ only for $\mathrm{Mn}^{4+}$ spectra. These minor peaks are also observed in previous studies (e.g. de Groot et al. 2010; Cuartero et al. 2016; Risch et al. 2017), especially on Mn-oxide spectra, and are influenced by the Mn valence and coordination environment, the crystal field strength, the nature and the length of the metal-ligand bonds, and the intra-atomic $3 d-3 d$ and $2 p-3 d$ Coulomb and spin234 orbit interactions in the $2 p$ core and $3 d$ orbitals.

235 Here, no complex calculations or multiplet analyses were used to describe spectrum shape in detail as the aim of the present study is to propose an easy-to-use approach to empirically map the Mn valence in silicates. However, some comments can be made to explain (i) the general 238 shape of the Mn-silicate spectra and (ii) the great similarity of them with Mn-oxide spectra. 
240 (noted dxy, dxz, dyz) and two have lobes on the axes (noted $\mathrm{dz}^{2}$ and $d x^{2}-\mathrm{y}^{2}$ ). In octahedral 241 coordination site, the 6 ligands approach Mn along the axes, increasing by electrostatic 242 repulsion the energy of $\mathrm{dz}^{2}$ and $\mathrm{dx}^{2}-\mathrm{y}^{2}$ orbitals (called $\mathrm{e}_{\mathrm{g}}$ ). Conversely, $\mathrm{dxy}, \mathrm{dxz}$, dyz orbitals 243 (called $\mathrm{t}_{2 \mathrm{~g}}$ ) point between the ligands, that lowered their energies. This difference of energy 244 between $e_{g}$ and $t_{2 g}$ orbital groups defines the crystal field strength ( $\Delta_{o}$ or 10Dq) (Burns 1993). 245 In the case of 6 coordinated $\mathrm{Mn}^{2+}$, the $\mathrm{t}_{2 \mathrm{~g}}$ spectral contribution is often assigned to the $\mathrm{L}_{3}-\mathrm{a}$ 246 minor peak, while $\mathrm{e}_{\mathrm{g}}$ is associated to the $\mathrm{L}_{3}$-b major peak (Garvie and Craven 1994; de Groot 247 et al. 1994), 10Dq can be deducting from the energy distance between these two peaks. In the 248 Figure 2, focused on the $\mathrm{L}_{3}$-edge part of $\mathrm{Mn}^{2+}$ absorption spectra (edge jump steps were 249 subtracted), the energy gap between $\mathrm{L}_{3}-\mathrm{a}$ and $\mathrm{L}_{3}-\mathrm{b}$ is very weak $(<1 \mathrm{eV})$, suggesting a low $25010 \mathrm{Dq}$ value. The comparison with $10 \mathrm{Dq}$ calculations and estimates from experiments 251 previously published (Garvie and Craven 1994; Garvie et al. 1994; Pérez-Dieste et al. 2004) 252 confirms that $10 \mathrm{Dq}$ value is probably around 0.5 or $1 \mathrm{eV}$. The energy difference between $\mathrm{t}_{2 \mathrm{~g}}$ 253 and $e_{\mathrm{g}}$ orbital groups remains therefore weak enough for Mn to be in high-spin state (Burns 254 1993), which is the most common spin configuration for Mn (Garvie and Craven 1994; de 255 Groot 1994). The Figure 2 also shows that the energy position of $\mathrm{L}_{3}$-a is always the same 256 whatever the $\mathrm{Mn}^{2+}$ mineral studied in our conditions, but that its intensity (related to $\mathrm{L}_{3}-\mathrm{b}$ 257 major peak intensity) is variable. This observation is also suitable for other minor peaks $\mathrm{L}_{3}-\mathrm{d}$ 258 and $\mathrm{L}_{3}-\mathrm{g}$, suggesting the contribution of another significant factors. In fact, $\mathrm{Mn}^{2+}$ in rhodonite, 259 ardennite and jacobsite is located in different coordination sites, with different Mn-ligand 260 bond length and different type of ligands. In rhodonite, $\mathrm{Mn}^{2+}$ occupies octahedral sites slightly 261 distorted, elongated, due to the global structure, linked to 6 O (Smyth and Bish 1988). This 262 configuration leads to an energy splitting between $\mathrm{dx}^{2}-\mathrm{y}^{2}$ and $\mathrm{dz}^{2}$ orbitals $\left(E_{\mathrm{dx}^{2}-\mathrm{y}^{2}}>E_{\mathrm{dz}^{2}}\right)$ on the 263 one hand, and between dxy and dxz, dyz orbitals $\left(E_{\mathrm{dxy}}>E_{\mathrm{dxz}}\right.$ and $\left.E_{\mathrm{dyz}}\right)$ on the other hand. In 264 ardennite, $\mathrm{Mn}^{2+}$ is located in large polyhedron with a 6 or 7 coordination configuration, with $265 \mathrm{O}$ and $\mathrm{OH}$ as ligands (Donnay and Allmann 1968), also implying a substantial change in 
orbital energies. In jacobsite, $\mathrm{Mn}^{2+}$ is surrounded by $4 \mathrm{O}$ in a tetrahedral site. But in this case,

267 the 4 ligands are closer to the $d x y, d x z$, dyz orbitals $\left(t_{2}\right)$ than to the $\mathrm{dz}^{2}, \mathrm{dx}^{2}-\mathrm{y}^{2}$ orbitals (e),

268 leading to an inversion of the splitting energy, $\mathrm{t}_{2}$ orbital group having higher energy than $\mathrm{e}$

269 orbital group (Burns 1993). Differences in spectrum shapes, especially the intensities of $\mathrm{t}_{2 \mathrm{~g}}$ or

$270 \mathrm{t}_{\mathrm{g}}-\mathrm{L}_{3}-\mathrm{a}$ (virtually disappeared in the case of jacobsite), $\mathrm{L}_{3}-\mathrm{d}$ and $\mathrm{L}_{3}-\mathrm{g}$ peaks, must be related

271 to the coordination and the ligands of Mn. From an empirical point of view, the intensity of

272 minor peaks decreases proportionally to the number of Mn-O bonds. On the other hand, the

273 similarity of $\mathrm{Mn}$-silicates (i.e. $\mathrm{Mn}^{2+}, \mathrm{Mn}^{3+}$ and $\mathrm{Mn}^{4+}$-silicates) and Mn-oxides spectra (from

274 this study and literature) tends to indicate that, as a first approximation, the extended atomic

275 environment (i.e. beyond the coordination site receiving $\mathrm{Mn}$ ) has negligible influence

276 compared to that of the near coordination.

Consequently, an empirical calibration linking a spectral parameter to the Mn mean

278 valence must be mainly based on major peaks, most sensitive to redox, without taking into

279 account an energy window (as white line ratio method) that might include minor peaks, most

280 sensitive to the Mn coordination and the surrounding atomic environment. An empirical

281 calibration is possible especially since the 10Dq is weak (van der Laan and Kirkman 1992).

283 3.2. Mn redox state estimation from $\mathrm{L}_{2,3}$-edge XANES spectra

284 As three valence states of Mn could be present in silicates, it is not possible to 285 determine easily, directly and empirically the relative proportion of each of them. As an 286 alternative, XANES spectra allow to assess the Mn mean valence which, coupled to a 287 structural formula obtained with an independent method, gives a strong indication of the 288 likely $\mathrm{xMn}^{2+}+\mathrm{yMn}^{3+}+\mathrm{zMn}^{4+}$ combination.

As referenced in the Figure 1, the main variation in the XANES spectra of silicates with the $\mathrm{Mn}$ valence involves the energy position of the $\mathrm{L}_{3}$ major peak. More precisely, the $\mathrm{L}_{3}$

291 major peak shifts to higher energies with increasing Mn charge, by a step of 1.4-1.6 eV.

292 However, because this step and Mn valence are not linearly linked, Risch et al. (2017) prefer 
to use the center of gravity of the $\mathrm{L}_{3}$-edge. From Mn-oxides, authors propose a linear

294 correlation implying to take in consideration the $\mathrm{L}_{3}$ minor peaks in addition to major peaks. A 295 such correlation was established here for silicates (Figure 3), and demonstrates the influence 296 of minor peaks, i.e. of the type of coordination sites in which Mn occurs. Considering only the 297 mineral phases where Mn occupies octahedral sites (piemontite, rhodonite) and $\mathrm{Mn}^{4+}$-silicate, 298 the relationship between nominal Mn valence and the $\mathrm{L}_{3}$ center of gravity is linear, with a $\mathrm{R}^{2}$ $299=1$. However, taking into account the ardennite in which Mn occupies large polyhedron or 300 jacobsite in which $\mathrm{Mn}$ is in tetrahedral sites, the energy position of the $\mathrm{L}_{3}$ center of gravity for $301 \mathrm{Mn}^{2+}$ phases depends on $\mathrm{L}_{3}-\mathrm{a}, \mathrm{L}_{3}-\mathrm{d}$ and $\mathrm{L}_{3}-\mathrm{g}$ peak weight and not only of $\mathrm{Mn}$ redox state.

302 Mainly, the $\mathrm{L}_{3}$ center of gravity is a spectral parameter including a peak area, not extractable 303 from a stack. This approach therefore does not allow to easily map the Mn valence from 304 STXM-XANES data. In order to construct a redox map, it becomes therefore necessary to propose a new purely-empirical calibration of Mn valence with a simple spectral parameter, using selected energy points (and not a spectral surface as white line ratio or center of gravity), that does not need to have any physical significance (as an intensity ratio). Considering only the silicates (jacobsite is excluded) and the 13 identified peaks (Figure 1), 78 ratios of two peak intensities can be calculated, plus their inverses, namely 156 possibilities. But only 12 peak intensity ratios are in correlation with the Mn valence with a coefficient of determination higher than 0.98. In fact, the $\mathrm{R}^{2}$ is very poor for intensity ratios implying major peaks of $\mathrm{Mn}^{3+}$ and minor peaks of $\mathrm{Mn}^{2+}$ (Figure 2). On the 12 peak intensity ratios correlated to Mn valence, 3 only used peaks from $\mathrm{L}_{3}$ peak, 6 only used peaks from $\mathrm{L}_{2}$ peak, and 3 used peaks from $\mathrm{L}_{3}$ and $\mathrm{L}_{2}$ peaks. Among them, we prefer those using peaks common to several valences and major

316 peaks. Two correlations are therefore selected as calibration. The selected spectral parameter in the first calibration is a ratio between the intensities at two energy points of the $\mathrm{L}_{2}$-edge, i.e. 318 at $\mathrm{L}_{2}-\mathrm{a}$ in $\mathrm{Mn}^{2+}$ spectra $(651.7 \mathrm{eV})$ and at the $\mathrm{L}_{2}$-e major peak in $\mathrm{Mn}^{4+}$ spectra $(655.2 \mathrm{eV})$. The spectral parameter is then expressed as follows: 
$321 \quad R_{L_{2}}=\frac{I(\text { at } 655.2 \mathrm{eV})}{I(\text { at } 651.7 \mathrm{eV})}$

323 From this parameter, the first calibration equation is (Figure 4a):

325 Mn mean valence $=\frac{R_{L_{2}}+6.705}{3.512}$

327 It shows a coefficient of determination $\left(\mathrm{R}^{2}\right)$ of 0.999 . The same $R_{L 2}$ value is obtained for

328 ardennite and rhodonite (and jacobsite, not used for calibration), showing that $\mathrm{R}^{2}$ is not

329 influenced by the Mn atomic environment but only by the Mn valence. This perfect

330 correlation can be used to map Mn valence on unknown samples, since only two images (at

331 fixed energy, i.e. 651.7 and $655.2 \mathrm{eV}$ ) are required.

The spectral parameter defined in the second calibration is the ratio between the

333 intensity at $\mathrm{L}_{3}$-egde energy point (i.e. $641.6 \mathrm{eV}$, the energy position of the $\mathrm{L}_{3}$-b major peak of

$334 \mathrm{Mn}^{2+}$ spectra) and the intensity at $\mathrm{L}_{2}$-edge energy point (i.e. $655.2 \mathrm{eV}$, the energy position of

335 the $\mathrm{L}_{2}$-e major peak of $\mathrm{Mn}^{4+}$ spectra). The calibration equation is expressed as follows (Figure $3364 \mathrm{~b})$ :

338 Mn mean valence $=\frac{R_{L_{2,3}}+0.669}{0.386}$

339 with

$340 \quad R_{L_{2,3}}=\frac{I(\text { at } 655.2 \mathrm{eV})}{I(\text { at } 641.6 \mathrm{eV})}$

342 The coefficient of determination for this second calibration $\left(\mathrm{R}^{2}\right)$ is 0.984 , slightly lower than

343 the one of the first calibration. The difference between $R_{L 2,3}$ values for rhodonite and

344 ardennite (and jacobsite) suggests a contribution of Mn atomic environment in addition to the

345 Mn valence dependence. However, taking an intensity on the $\mathrm{L}_{3}$-edge (which is more intense 
than the $\mathrm{L}_{2}$ ) and one on the $\mathrm{L}_{2}$-edge improves the signal to noise ratio. As for the first

347 correlation proposed, the construction of a Mn valence map from STXM-XANES data is made possible by equation 3 .

\subsection{STXM-XANES coupling: Mn redox mapping}

The scanning properties of the microscope allow to record a stack of 125 energy images over the 635-660 eV with a spectral resolution of $0.2 \mathrm{eV}$. Equations 2 and 3 permit the Mn mean valence to be estimated from the spectrum intensities at two energies. This gives the possibility to easily map the Mn valence from two energy images, and use one of the two calibrations proposed.

In fact, two other XANES images are required in addition to the two images used for mapping, in order to subtract the background at each pixel of the images. Therefore, only four energy images should be selected to calculate the $R$ parameter. In the Figure 5, the calibration procedure that uses the equation 3 and the $R_{L 2,3}$ parameter is drawn as example (piemontite sample). It is obtained by extracting one image at $641.6 \mathrm{eV}$, one at $655.2 \mathrm{eV}$, one in the preedge (to apply the "linear background correction"' at each pixel of the $641.6 \mathrm{eV}$ image), and one beyond the energy corresponding to the $\mathrm{L}_{2}$ peak (to remove the linear background and the second edge step of the arctan function at each pixel of the $655.2 \mathrm{eV}$ image). The ratio of corrected 641.6 and $655.2 \mathrm{eV}$ images can then be used to determine the $R_{L 2,3}$ for each pixel and to obtain the map of $\mathrm{Mn}$ redox state. In this way, the linear background is represented by only one energy at one energy position, so this point should be fairly close to the first peak (638 eV in Figure 5). In the case of spectra with a strong background noise, it is possible to make an "image average" (giving an average value of the linear pre-peak background) by selecting about 10 images between 625 and $639 \mathrm{eV}$, by adding them and then by dividing the resulting "image sum" by 10 thanks to the aXis2000 software.

If the equation 2 is chosen for calibration, the images required to calculate the $R_{L 2}$ parameter need to be selected at $651.7 \mathrm{eV}\left(\mathrm{L}_{2}-\mathrm{a}\right)$, at $655.6 \mathrm{eV}\left(\mathrm{L}_{2}-\mathrm{e}\right)$, at the inflexion point 
between the $\mathrm{L}_{3}$ peak and the $\mathrm{L}_{2}$ peak (to remove the background from the $651.7 \mathrm{eV}$ ), and one

374 beyond the $\mathrm{L}_{2}$ peak (to remove the linear background and the second edge step of the arctan

375 function for each pixel of the $655.2 \mathrm{eV}$ image). By applying the same procedure as before, the

376 Mn map can be reconstructed only from the $\mathrm{L}_{2}$-edge data.

377 Resulting quantitative Mn redox maps are a useful tool to identify the Mn mean

378 valence of unknown nanometric particles, but have some limitations. On a map built from

$379 R_{L 2,3}$ parameter for a no-pure piemontite sample constructed with equation 3 (Figure 6 ), the

380 Mn-free crystallites appear in white (Figure 5G and Figure 6) while in areas where the particle

381 is too thick and/or highly concentrated in Mn, valence is overestimated (Figure 6B). In the

382 first case, the absence of Mn leads to calculate the ratio between two too weak absorption

383 pixels (Figure 5E and F). In the second case, a too high X-ray absorption cause an absorption

384 saturation of the $\mathrm{L}_{3}$ peak, which is more intense than the $\mathrm{L}_{2}$ peak. This phenomenon generates

385 a nonlinear response of the absorption detection, artificially modifying the relative peak

386 intensities, affecting the $R_{L 2,3}$ calculation and overestimating the Mn valence. Although more

387 sensitive to the signal/noise ratio, the use of the $R_{L 2}$ parameter and equation 2 to map the $\mathrm{Mn}$

388 valence, based exclusively on the $\mathrm{L}_{2}$ peak, may provide a favourable way to circumvent

389 absorption saturation issues encountered with the $\mathrm{L}_{3}$ peak (Figure 6C).

390 The spatial averaging effect of the X-ray beam over the pixel size (i.e., $40 \mathrm{~nm}$ ) must

391 also be taking into account. This effect fixes the limit of the minimum distance over which

392 phase contacts or phase rims can be discriminated.

Surpassing these limitations easily identifiable, the STXM-based XANES quantitative

394 map becomes a precise tool, giving an estimate of Mn valence with a high spatial resolution,

395 as demonstrated by the map of piemontite in the Figure 6.

3.4. Assessment of saturation and beam damage effects

Although EELS is known to cause more damage than STXM on the structure of

399 minerals (e.g. de Groot et al. 2010), the latter is nonetheless a method that damages particles 
during analysis if precautions are not taken. Potentially, the repeated scan of particles at each

401

402

403

404

405

406

407

408

409

energy point of a spectrum can altered the structure of the crystallites, and consequently the

Mn mean valence estimate. A stack recorded on a $5 \times 5 \mu \mathrm{m}$ area, obtained with a spatial resolution of $50 \mathrm{~nm}$, a spectral resolution of $0.2 \mathrm{eV}$ and a dwell time of $5 \mathrm{~ms}$ per energy- and image- point results in a total analysis time of 2.5 hours (dead time excluded) and of $0.875 \mathrm{~s}$ per image-point. To evaluate beam damages, spectral changes at the $\mathrm{Mn} \mathrm{L}_{2,3}$-edges were monitored with increasing dwell times, from 1 to $20 \mathrm{~ms}$ per energy- and image- point. The resulting XANES spectra do not show significant changes, while $R_{L 2}$ and $R_{L 2,3}$ parameters are only slightly affected, varying by less than $5 \%$. Consequently, the effect of beam damages on the $\mathrm{Mn}$ valence estimate is negligible in the typical dwell time range used during routine analyses.

The saturation of spectrum can also alter assessment of $R_{L 2}$ and $R_{L 2,3}$ parameters (see section 3.3). This phenomenon occurs when particles are too thick or too rich in $\mathrm{Mn}$ (or a combination of both), leading to a distortion of the spectrum. Hanhan et al. (2009) for Ca and Bourdelle et al. (2013) for Fe proposed to evaluate the maximum intensity of the major peak not to be exceeded to avoid saturation effect. Applying a similar approach, the maximum Mn $\mathrm{L}_{3}$ peak intensity, below which the $\mathrm{L}_{3} / \mathrm{L}_{2}$ peak intensity ratio varies linearly and the spectrum is undistorted, was determined. For this, a stack was recorded on a powder of piemontite sample $\left(\mathrm{Mn}^{3+}\right)$ with particles of various thicknesses. Figure 7 plots the intensity of the $\mathrm{L}_{3}$ major peak according to the one of $\mathrm{L}_{2}$ major peak for each image-point. The intensities of these two peaks increase linearly until $\sim 0.25$ OD. When the particle is thick enough for the $\mathrm{L}_{3}$ major peak intensity to exceed $0.25 \mathrm{OD}$, the $\mathrm{L}_{3} / \mathrm{L}_{2}$ intensity ratio no longer evolves linearly, i.e. the intensity of $\mathrm{L}_{2}$ major peak increases faster than that of $\mathrm{L}_{3}$ major peak, reflecting the spectra distortion for the considered image-points. This observation is also valid for $\mathrm{Mn}^{2+}$ and $\mathrm{Mn}^{4+}$ spectra. Consequently, all the quantitative data in this study were therefore obtained from areas presenting a $\mathrm{L}_{3}$ major peak intensity lower than $0.25 \mathrm{OD}$. It should be noted that $\mathrm{Mn}$ is much more sensitive to saturation phenomena than $\mathrm{Fe}$ (saturation effects at $>1.5 \mathrm{OD}$ at 
the Fe L 2,3 -edges; Bourdelle et al. 2013), i.e. saturation effects appear at relatively low Mn content (concentration or weak sample thickness). On an indicative basis, piemontite, which is a phase that is not very rich in Mn, presents saturated spectra for a crystallite thickness higher than $\sim 150 \mathrm{~nm}$, while Mn-rich jacobsite shows saturation effects on spectrum when crystallite thickness is around $70 \mathrm{~nm}$.

The crystal orientation compared with the direction of polarisation of the X-ray beam may also influence the spectrum shape. This process is called linear dichroism (Benzerara et al. 2011), and can be thwart using a circular polarized beam as here. The residual dichroism effect was evaluated by comparing spectra from different piemontite particles with various orientation. No change in spectrum shape was observed, and the impact of particle orientation on the Mn mean valence estimate remained undetectable.

\section{Conclusion}

In the present work, we explore the possibility to construct quantitative Mn redox maps for silicates using the STXM coupled with XANES spectroscopy at the $\mathrm{Mn} \mathrm{L}_{2,3}$-edges. With fairly limited precautions, we demonstrate that this type of maps could be obtained from two easy-to-use empirical calibrations linking the Mn mean valence to a simple ratio of intensities from selected energy positions. We applied this approach on a mix of piemontite and no-Mn phase sample, demonstrating the potential of it to assess the Mn valence at the nanoscale through micrometric areas. Even if calibrations and map construction have yet to be tested on silicates containing Mn under several oxidation states, as Mn-phyllosilicates, these results pave the way for the study of nanochemical zonations in heterogeneous silicates.

\section{Acknowledgements}

We are most grateful to the PSI SLS synchrotron, especially Benjamin Watts (PolLux beamline) for technical advice. Thanks are extended to Philippe Recourt (LOG, Univ. Lille) for sample preparation and to Francis Coune for providing ardennite sample. The authors 
wish also to thank the editor and the two anonymous reviewers for comments and suggestions

455 that improved the paper. This study was financially supported by LGCgE.

456

457

458

459

460

461

462

463

464

465

466

467

468

469

470

471

472

473

474

475

476

477

478

\section{References}

Albee AL, Chodos AA (1970) Semiquantitaive electron microscope determination of $\mathrm{Fe} 2+/ \mathrm{Fe} 3+$ and $\mathrm{Mn} 2+/ \mathrm{Mn} 3+$ in oxides and silicates and its application to petrologic problems. Am Mineral 55:491-501.

Benzerara K, Menguy N, Obst M, Stolarski J, Mazur M, Tylisczak T, Brown GE Jr, Meibom A (2011) Study of the crystallographic architecture of corals at the nanoscale by scanning transmission X-ray microscopy and transmission electron microscopy. Ultramicroscopy 111:1268-1275

Bobos I, Noronha F, Mateus A (2018) Fe-, Fe,Mn- and Fe,Mg-chlorite: a genetic linkage to $\mathrm{W},(\mathrm{Cu}, \mathrm{Mo})$ mineralization in the magmatic-hydrothermal system at Borralha, northern Portugal. Mineral Mag 82:S259-S279

Bosi F, Biagioni C, Pasero M (2019) Nomenclature and classification of the spinel supergroup. Eur J Mineral 31:183-192

Bourdelle F, Beyssac O, Parra T, Chopin C (2018) Nanoscale chemical zoning of chlorite and implications for low-temperature thermometry: Application to the Glarus Alps (Switzerland). Lithos 314:551-561

Bourdelle F, Benzerara K, Beyssac O, Cosmidis J, Neuville DR, Brown GE, Paineau E (2013) Quantification of the ferric/ferrous iron ratio in silicates by scanning transmission X-ray microscopy at the Fe L-2,L-3 edges. Contrib Mineral Petrol 166:423-434

Brotton SJ, Shapiro R, van der Laan G, Guo J, Glans PA, Ajello JM (2007) Valence state fossils in Proterozoic stromatolites by L-edge X-ray absorption spectroscopy. J Geophys Res Biogeosci 112:G3 
Burns R (1993) Mineralogical Applications of Crystal Field Theory (Cambridge Topics in Mineral Physics and Chemistry). Cambridge: Cambridge University Press. doi:10.1017/CBO9780511524899

Chen CT, Idzerda YU, Lin HJ, Smith NV, Meigs G, Chaban E, Ho GH, Pellegrin E, Sette F (1995) Experimental confirmation of the X-ray magnetic circular-dichroism sum-rules for iron and cobalt. Phys Rev Lett 75:152-155

Cuartero V, Lafuerza S, Rovezzi M, Garcia J, Blasco J, Subias G, Jiménez E (2016) X-ray absorption and emission spectroscopy study of Mn and Co valence and spin states in

$$
\mathrm{TbMn}_{1-\mathrm{x}} \mathrm{Co}_{\mathrm{x}} \mathrm{O}_{3} \text {. Phys rev B 94:155117 }
$$

de Groot FMF, de Smit E, van Schooneveld MM, Aramburo LR, Weckhuysen BM (2010) Insitu scanning transmission X-ray microscopy of catalytic solids and related nanomaterials.

$$
\text { Chem Phys Chem 11:951-962 }
$$

de Groot FMF (1994) X-ray absorption and dichroism of transition metals and their

$$
\text { compounds. J Electron Spectros Relat Phenomena 67:529-622 }
$$

Donnay G, Allmann R (1968) Si3O10 Groups in the Crystal Structure of Ardennite. Acta

$$
\text { Cryst B 24:845 }
$$

Garvie LAJ, Craven AJ (1994) High-resolution parallel electron energy-loss spectroscopy of Mn L2,3-edges in inorganic manganese compounds. Phys Chem Miner 21:191-206

Garvie LAJ, Craven AJ, Brydson R (1994) Use of electron-energy loss near-edge fine

$$
\text { structure in the study of minerals. Am Mineral 79:411-425 }
$$

Hanhan S, Smith AM, Obst M, Hitchcock AP (2009) Optimization of analysis of soft X-ray

$$
\text { spectromicroscopy at the Ca 2p edge. } J \text { Electron Spectros 173:44-49 }
$$

Hitchcock AP (2012) aXis 2000 analysis of X-ray images and spectra. McMaster University,

$$
\text { Hamilton }
$$

Ilton ES, Post JE, Heaney PJ, Ling FT, Kerisit SN (2016) XPS determination of Mn oxidation

$$
\text { states in Mn (hydr)oxides. Appl Surf Sci 366:475-485 }
$$


505

506

507

508

509

510

511

512

513

514

515

516

517

518

519

520

521

522

523

524

525

526

527

528

529

Inoue A, Inoue S, Utada M (2018) Application of chlorite thermometry to estimation of formation temperature and redox conditions. Clay Miner 53:143-158

Kubin M, Guo M, Kroll T, Löchel H, Källman E, Baker ML, Mitzner R, Gul S, Kern J, Föhlisch A, Erko A, Bergmann U, Yachandra V, Yano J, Lundberg M, Wernet P (2018)

Probing the oxidation state of transition metal complexes: a case study on how charge and spin densities determine Mn L-edge X-ray absorption energies. Chem Sci 9:6813

Lauterbach S, McCammon CA, van Aken P, Langenhorst F, Seifert F (2000) Mossbauer and ELNES spectroscopy of $(\mathrm{Mg}, \mathrm{Fe})(\mathrm{Si}, \mathrm{Al}) \mathrm{O} 3$ perovskite: a highly oxidised component of the lower mantle. Contrib Mineral Petrol 138:17-26

Livi KJT, Lafferty B, Zhu M, Zhang S, Gaillot A-C, Sparks DL (2012) Electron Energy-Loss Safe-Dose Limits for Manganese Valence Measurements in Environmentally Relevant Manganese Oxides. Environ Sci Technol 46:970-976

Loomer D, Al T, Weaver L, Cogswell S (2007) Manganese valence imaging in Mn minerals at the nanoscale using STEM-EELS. Am Mineral 92:72-79

Manceau A, Gallup DL (2005) Nanometer-sized divalent manganese-hydrous silicate domains in geothermal brine precipitates. Am Mineral 90:371-381

Manceau A, Marcus MA, Grangeon S (2012) Determination of Mn valence states in mixedvalent manganates by XANES spectroscopy. Am Mineral 97:816-827

Morales F, de Groot FMF, Glatzel P, Kleimenov E, Bluhm H, Hävecker M, Knop-Gericke A, Weckhuysen BM (2004) In Situ X-ray Absorption of Co/Mn/TiO2 Catalysts for FischerTropsch Synthesis. J Phys Chem B 108:16201-16207

Nagashima M, Armbruster T (2010) Ardennite, tiragalloite and medaite: structural control of (As5+, V5+, Si4+)O4 tetrahedra in silicates. Mineral Mag 74:55-71

Nelson WR, Griffen DT (2005) Crystal chemistry of Zn-rich rhodonite ("fowlerite"). Am Mineral 90:969-983 
Nishida S, Kobayashi S, Kumamoto A, Ikeno H, Mizoguchi T, Tanaka I, Ikuhara Y,

531 Yamamoto T (2013) Effect of local coordination of Mn on Mn-L2,3 edge electron energy

532 loss spectrum. J Appl Phys 114:054906

533 Pecher K, McCubbery D, Kneedler E, Rothe J, Bargar J, Meigs G, Cox L, Nealson K, Tonner

534 B (2003) Quantitative charge state analysis of manganese biominerals in aqueous

535 suspension using Scanning Transmission X-ray Microscopy (STXM). Geochim

536 Cosmochim Acta 67:1089-1098

537 Pérez-Dieste V, Crain J N, Kirakosian A, McChesney J L, Arenholz E, Young A T, Denlinger

538 J D, Ederer D L, Callcott T A, Lopez-Rivera S A, Himpsel FJ (2004) Unoccupied orbitals

539 of 3d transition metals in ZnS. Phys Rev B 70:085205

540 Raabe J, Tzvetkov G, Flechsig U, Böge M, Jaggi A, Sarafimov B, Vernooij MGC,

541 Huthwelker T, Ade H, Kilcoyne D, Tyliszczak T, Fink RH, Quitmann C (2008) PolLux: A

542 new facility for soft X-ray spectromicroscopy at the Swiss Light Source. Rev Sci Instrum

$543 \quad 79$

544 Risch M, Stoerzinger KA, Han B, Regier TZ, Peak D, Sayed SY, Wei C, Xu Z, Shao-Horn Y

545 (2017) Redox Processes of Manganese Oxide in Catalyzing Oxygen Evolution and

546 Reduction: An in Situ Soft X- ray Absorption Spectroscopy Study. J Phys Chem C

$547 \quad 121: 17682-17692$

548 Smyth JR, Bish D L (1988) Crystal Structures and Cation Sites of the Rock-Forming Minerals

549 London and Boston (Unwin-Hyman Ltd.). Mineral Mag 52:733-734

550 Sussenberger A, Pospiech S, Schmidt ST (2018) [MnO vertical bar SiO2, Al2O3, FeO, MgO]

551 balanced log-ratio in chlorites: a tool for chemo-stratigraphic mapping and proxy for the

552 depositional environment. 16th International Clay Conference (ICC) Location: Granada.

$553 \quad$ Clay miner 53:351-375

554 Tan H, Verbeeck J, Abakumov A, van Tendeloo G (2012) Oxidation state and chemical shift

555 investigation in transition metal oxides by EELS. Ultramicroscopy 116:24-33 
van Aken PA, Liebscher B (2002) Quantification of ferrous/ferric ratios in minerals: new

557

558

559

$$
\text { evaluation schemes of Fe L-23 electron energy-loss near-edge spectra. Phys Chem Miner }
$$$$
\text { 29:188-200 }
$$

Van der Laan G, Kirkman IW (1992) The 2p absorption spectra of 3d transition metal compounds in tetrahedral and octahedral symmetry. J Phys: Condens Matter 4:4189-4204

Wang H, Friedrich S, Li L, Mao Z, Ge P, Balasubramanian M, Patil DS (2018) L-edge sum rule analysis on $3 \mathrm{~d}$ transition metal sites: from $\mathrm{d} 10$ to $\mathrm{d} 0$ and towards application to extremely dilute metallo-enzymes. Phys Chem Chem Phys 20:8166-8176

Zhang S, Livi KJT, Gaillot A-C, Stone AT, Veblen DR (2010) Determination of manganese valence states in $(\mathrm{Mn3}+, \mathrm{Mn} 4+)$ minerals by electron energy-loss spectroscopy. Am Mineral 95:1741-1746

\section{Figure captions}

Fig. 1 Representative XANES spectra at the $\mathrm{Mn} \mathrm{L}_{2,3}$-edges for the $\mathrm{Mn}$-silicates and jacobsite. The spectra have been normalised to the major $\mathrm{L}_{3}$ peak intensity, and some of the spectra have been shifted vertically for clarity (normalised intensity with arbitrary units). The vertical lines indicate major peaks (solid lines) and minor peaks (dashed lines). Each peak is indexed, redox states and core-excited final state configurations are mentioned

Fig. 2 Focus on $\mathrm{L}_{3}$-edge for $\mathrm{Mn}^{2+}$ phases (rhodonite, ardennite, jacobsite). The spectra have been normalised to the major $\mathrm{L}_{3}$ peak intensity. Coordination (number of $\mathrm{O}$ ligands and sites) is specified for each phases

Fig. $3 \mathrm{~L}_{3}$-edge center of gravity from XANES spectra versus Mn valence for the selected silicates. Error bars represent the standard deviation calculated on the base of 4 or 5 spectra for each sample. Value for jacobsite is given for information, but not taken into account for calibration calculation 
Fig. $4 \mathrm{~L}_{2,3}$-edge intensity ratio from XANES spectra versus Mn valence for the selected silicates. (A) $R_{L 2}$ ratio, using selected intensities at two energy points (i.e. 651.7 and $655.2 \mathrm{eV}$ ) of the $\mathrm{L}_{2}$-edge. (B) $R_{L 2,3}$ ratio, using selected intensities at one energy point (i.e. $641.6 \mathrm{eV}$ ) of the $\mathrm{L}_{3}$-edge and one energy point (i.e. $655.2 \mathrm{eV}$ ) of the $\mathrm{L}_{2}$-edge. Error bars represent the standard deviation calculated on the base of 4 or 5 spectra for each sample, i.e. 18 spectra in total. Values for jacobsite are given for information, but not taken into account for calibration calculation

Fig. 5 Determination of the Mn valence from 4 selected energy images: one image in the pre-edge (to apply the "linear background correction"' at each pixel of the image; image A), one at $641.6 \mathrm{eV}\left(\mathrm{L}_{3}-\mathrm{b}\right.$ major peak of $\mathrm{Mn}^{2+}$; image $\left.\mathrm{B}\right)$, one at $655.2 \mathrm{eV}\left(\mathrm{L}_{2}\right.$-e major peak of $\mathrm{Mn}^{4+}$; image $\left.\mathrm{C}\right)$ and one beyond the $\mathrm{L}_{2}$-edge (to remove the edge step of the arctan function; image $\mathrm{D}$ ). Finally, the ratio of the resulting 641.6 and $655.2 \mathrm{eV}$ images (E and F) can be used to determine the $R_{L 2,3}$ parameter at each pixel of the image and obtain Mn redox mapping (G). All images are OD images, where piemontite and no Mn-silicate are the light-grey and dark phases on image E, respectively. White scale: $1 \mu \mathrm{m}$

Fig. 6 Quantitative Mn redox nanomapping on particles from no-pure piemontite sample. A: optical density image at $641.6 \mathrm{eV}$, where the piemontite and no-Mn silicate particles are the light-grey and white phases, respectively. B: manganese redox mapping, calculated from the $R_{L 2,3}$ parameter coupled with the Eq. (3). C: manganese redox mapping, calculated from the $R_{L 2}$ parameter coupled with the Eq. (2). The spatial averaging effect of the $\mathrm{X}$-ray beam over the pixel size (i.e., $40 \mathrm{~nm}$ ) sets the limit of the minimum distance (turquoise rims, underlined by a yellow square). No-Mn silicates, identified by blue dashed polygon on the OD image, appear in white on the redox map B and in black for no $\mathrm{Mn}$ absorption on the redox map $\mathrm{C}$ and image $\mathrm{E}$ of the Fig. 5. Areas where the particle thickness is too 607 high to obtain no-saturated images (see section 3.4.) - highlighted by a purple polygon on the OD 608 image - lead to the overestimate of Mn valence (pink and red zones of the redox map B), up to the total saturation (appearing in white on the map). Areas presenting no-too-thick piemontite particles

610 (i.e. the rest of the OD image) appear in blue on the Mn redox maps, testifying of trivalent manganese 
612 Fig. 7 Difference, pixel by pixel, of intensity detected between the $\mathrm{L}_{3}$ major peak and the $\mathrm{L}_{2}$ major 613 peak images (in which a pre-edge image was subtracted) for a no-pure piemontite sample (4661

614 pixels). The dashed line was calculated from a quadratic equation. Insets: representative spectra and 615 optical density image $(641.6 \mathrm{eV})$ for a no-pure piemontite sample 


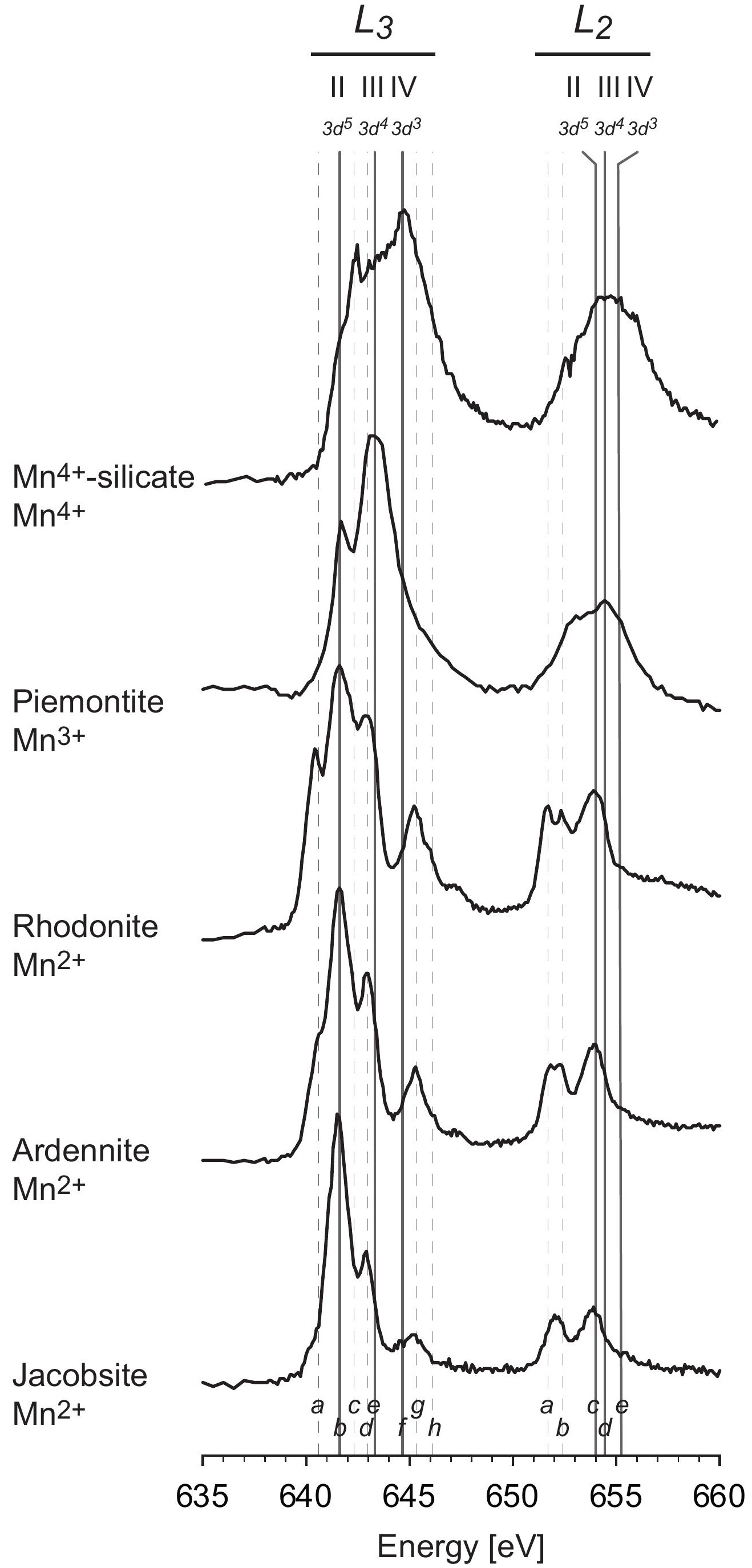




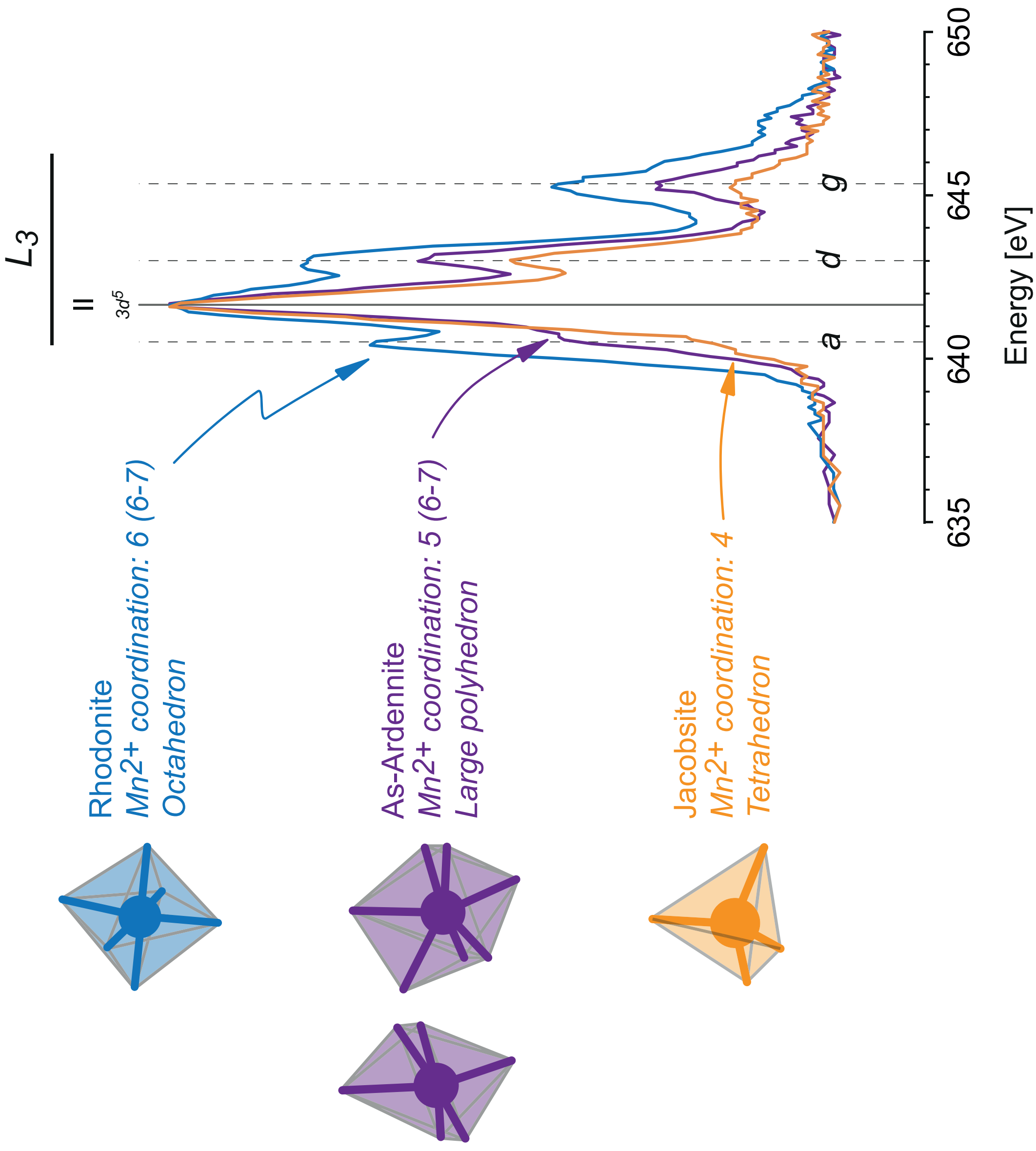

$=$

6

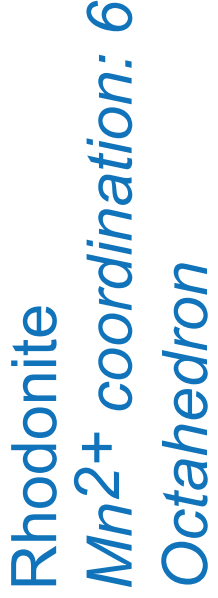

으

交志 क

$\dot{c} \approx \pi$

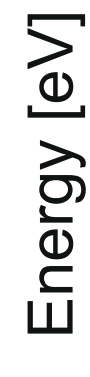

ใั त

$0 \leq \pm$

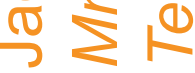



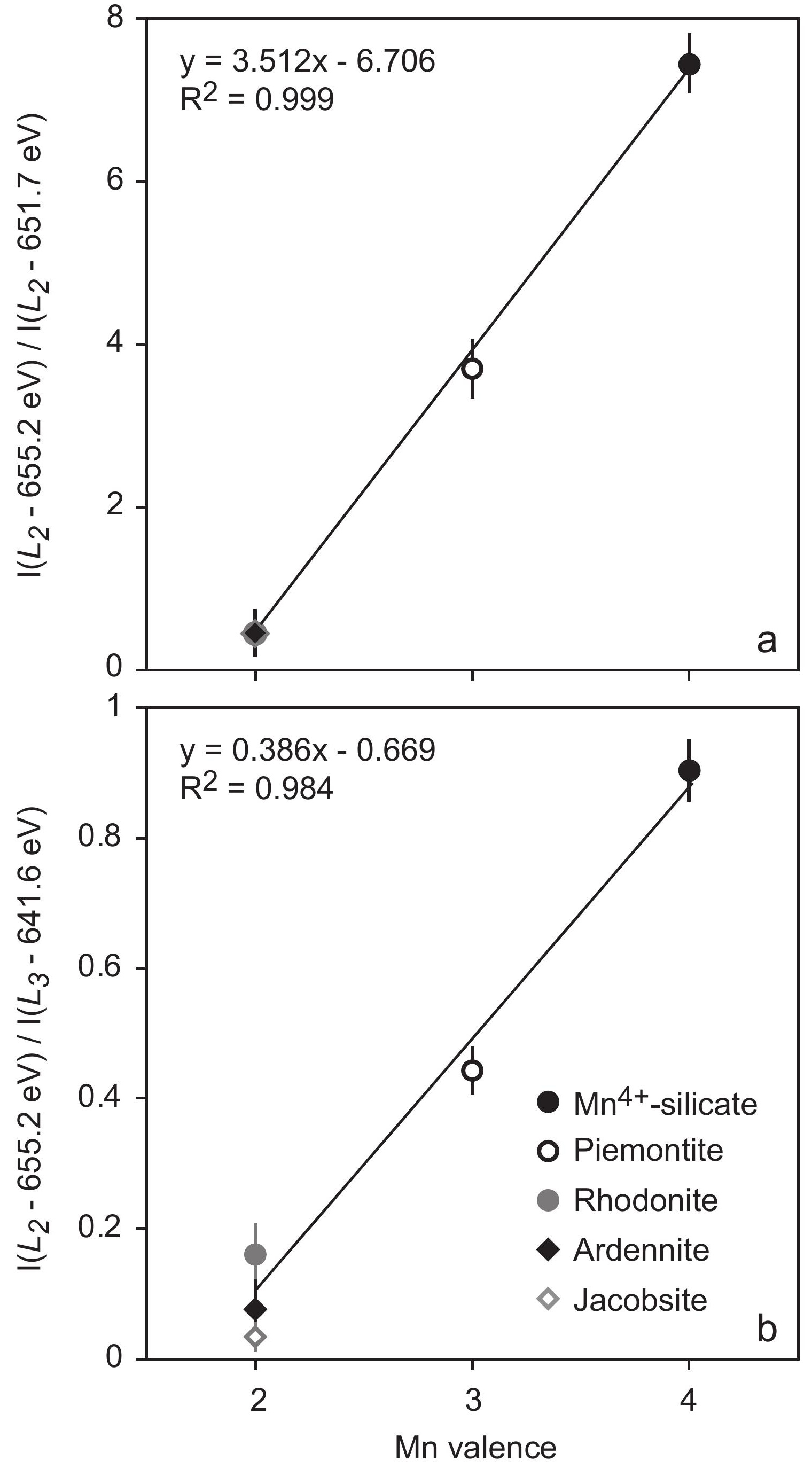


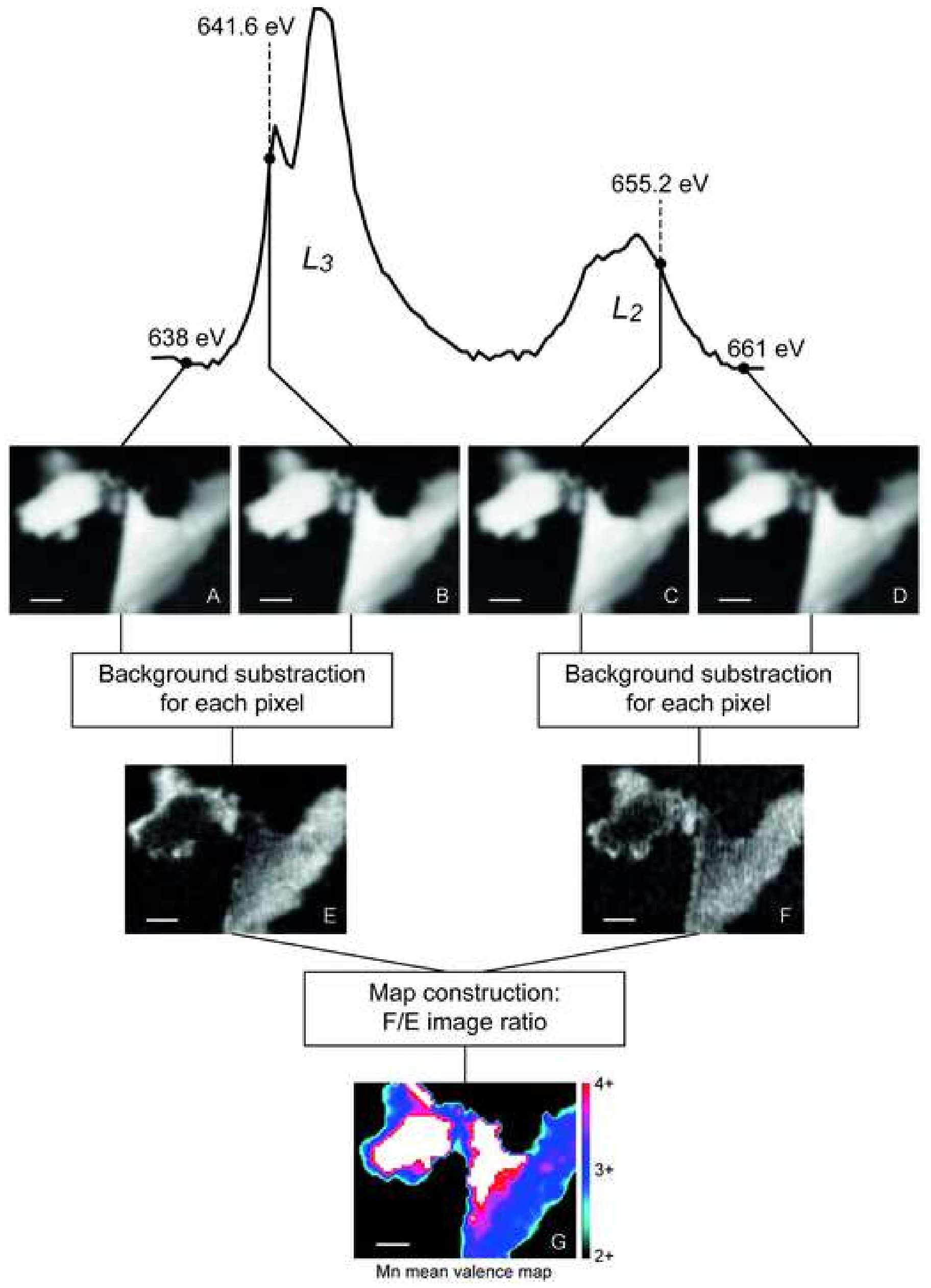



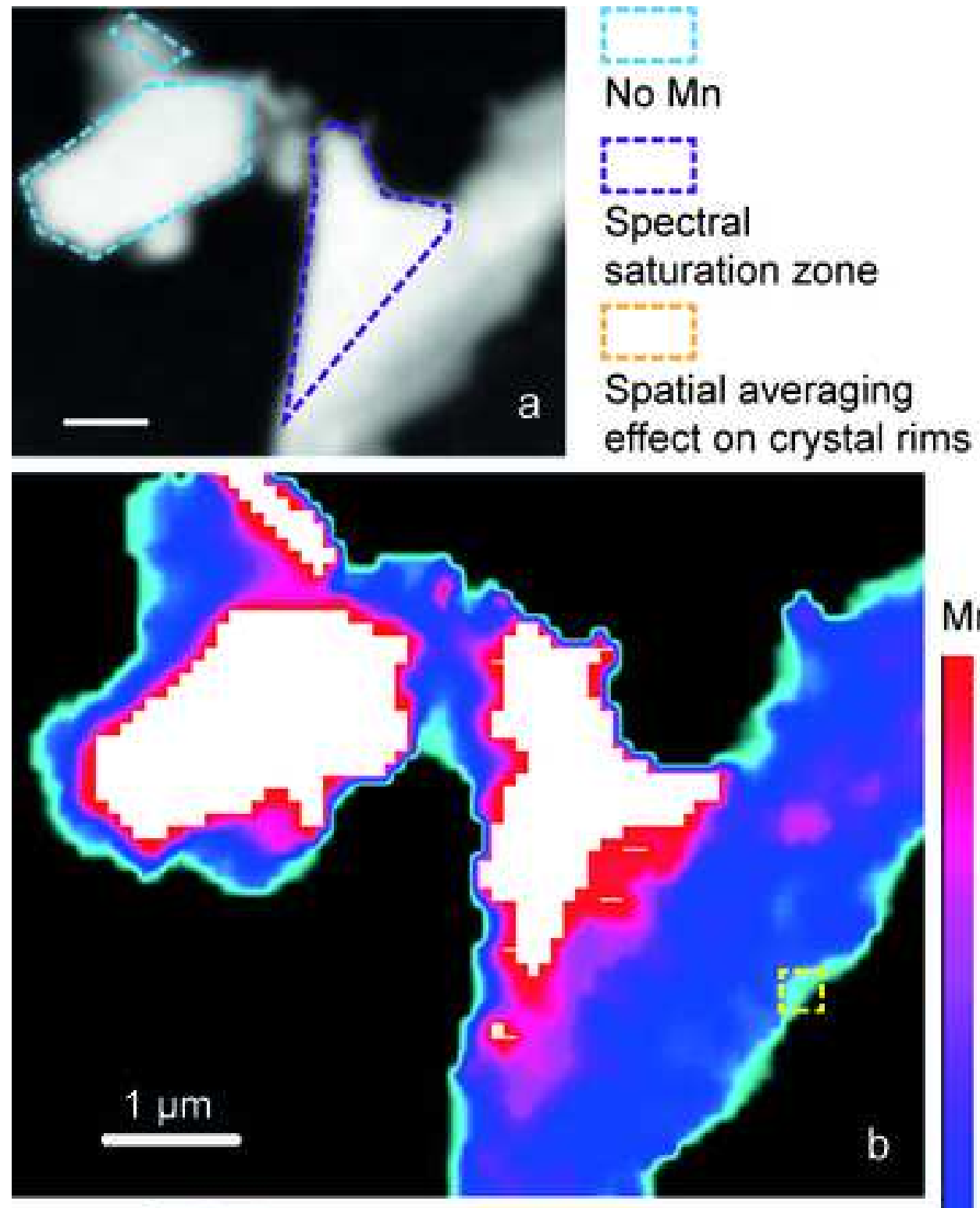

$\mathrm{Mn}^{\mathrm{X}+}$

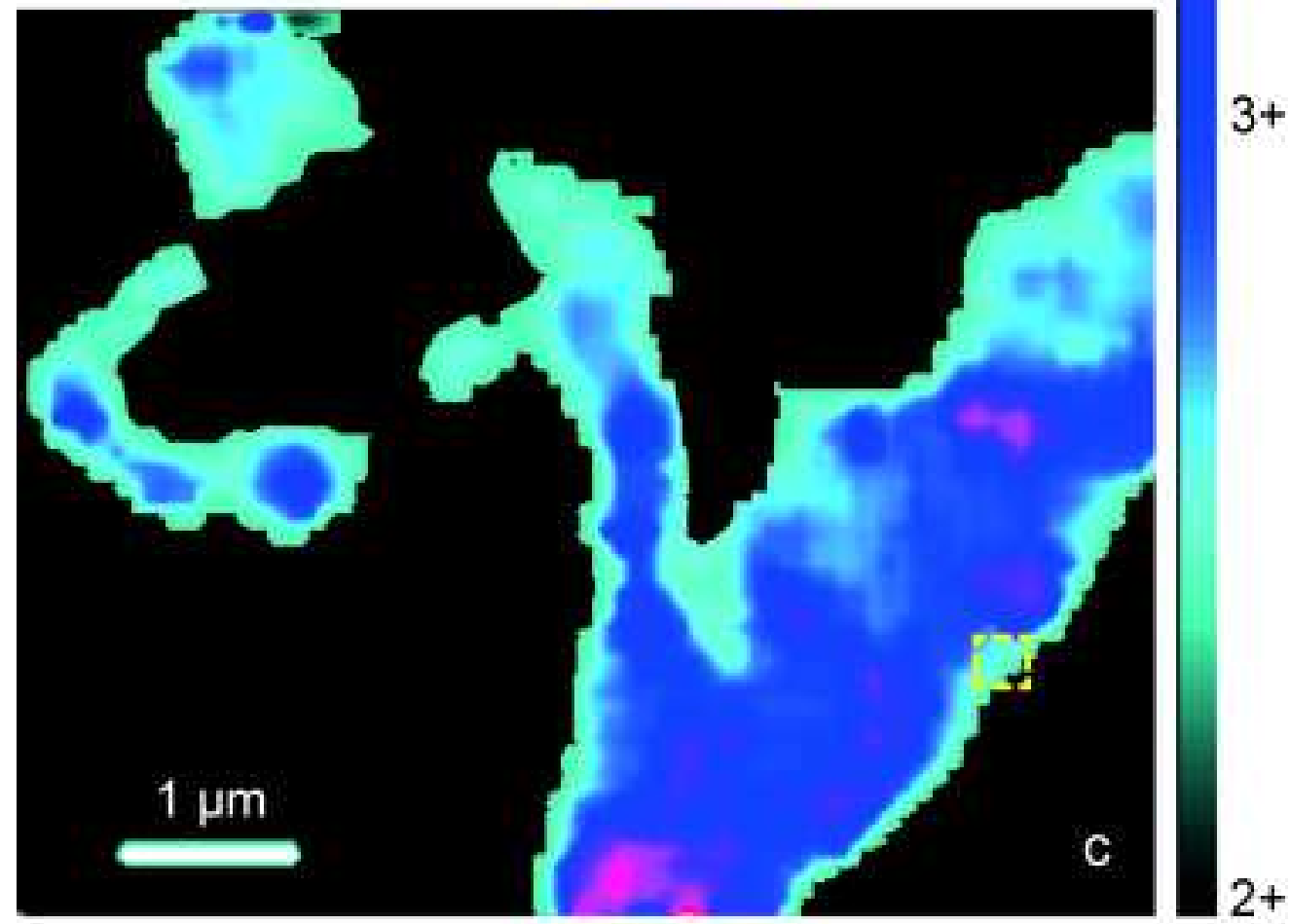




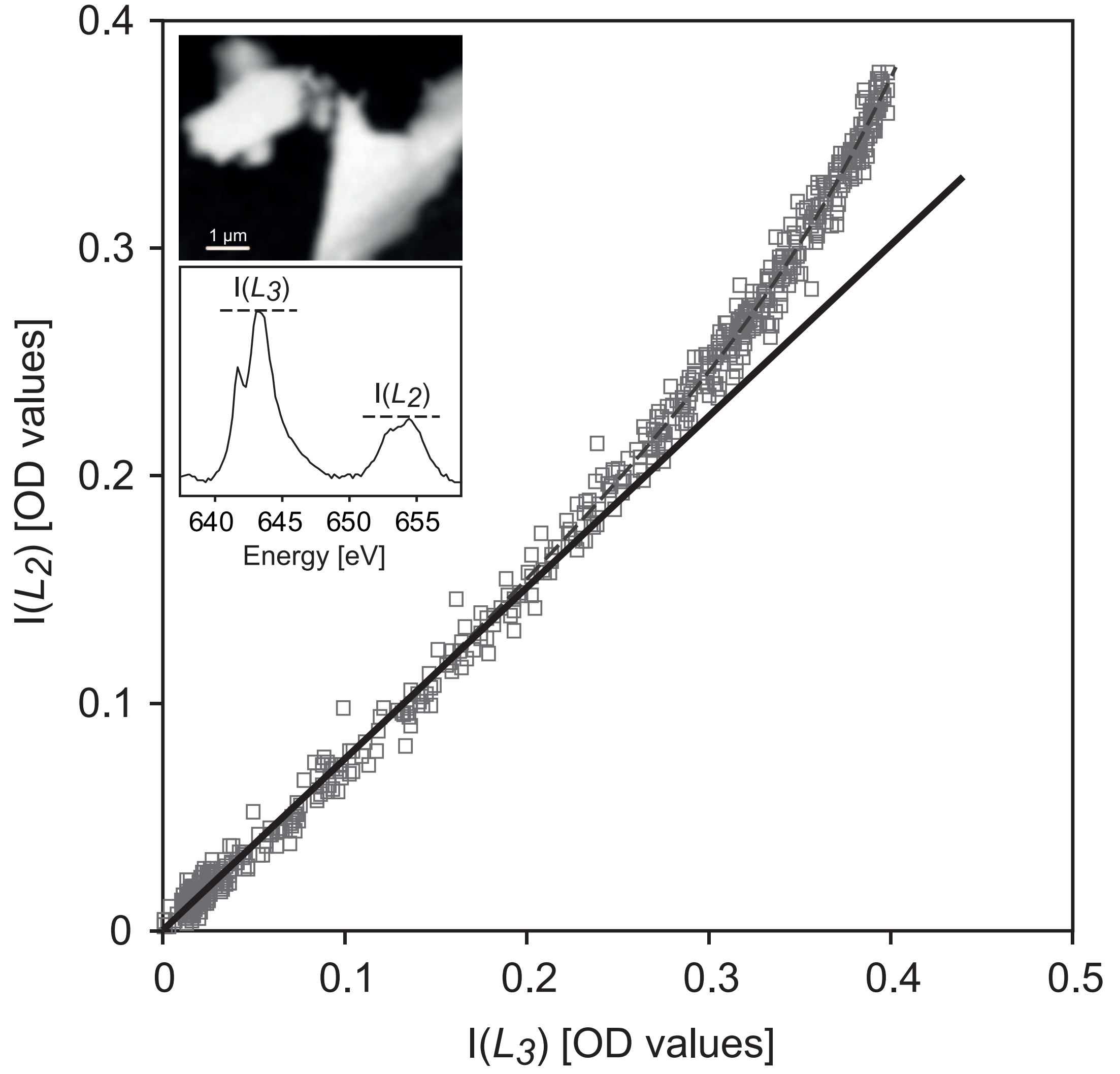

